\title{
Imagens em movimento nas aulas de história e o seu impacto no desenvolvimento de competências de autoaprendizagem em estudantes da educação básica
}

\section{Moving pictures in history classes and their impact on the development of self-learning skills in lower secondary education}

\author{
Miguel Pinheiro \\ Mestre em Ensino de História no $3^{\circ} \mathrm{CEB}$ e no ES \\ Universidade Coimbra, Faculdade de Letras - FLUC \\ Coimbra - Portugal \\ mpinheiro97@hotmail.com \\ iD \\ Sara Dias-Trindade \\ Doutoramento em História, Didática \\ Universidade Coimbra, Faculdade de Letras - FLUC \\ Centro de Estudos Interdisciplinares - CEIS20 \\ Coimbra - Portugal \\ sara.trindade@uc.pt \\ D Pedro Alves \\ Doutoramento em Comunicação Audiovisual \\ Escola das Artes da Universidade Católica Portuguesa - EA-UCP \\ Centro de Investigação em Ciência e Tecnologia das Artes - CITAR \\ Porto - Portugal \\ pmalves@ucp.pt
}

\begin{abstract}
Resumo: As imagens em movimento foram ganhando, com o tempo, cada vez mais importância na sociedade e, também, na educação. O cinema ou o filme documentário, por exemplo, têm a capacidade de representar de forma dinâmica certos acontecimentos ocorridos no mundo real e auxiliar na compreensão dos conteúdos lecionados, ao mesmo tempo que promove um ambiente descontraído e motivador. Com base neste pressuposto, este artigo tem como objetivo apresentar um estudo de caso qualitativo realizado com 14 estudantes de educação básica em Portugal, para avaliar de que forma as imagens em movimento contribuem para o desenvolvimento de competências de autoaprendizagem nas aulas de História nas dimensões consideradas: Aprendizagem Ativa, Iniciativa e Autonomia. Os resultados mostraram que a utilização desta estratégia pedagógica contribui para o desenvolvimento de competências de autoaprendizagem, sobretudo em relação à motivação para aprender, a autonomia e a iniciativa individual para aprofundar conhecimentos.
\end{abstract}

Palavras-chave: Imagens em Movimento. Cinema. História. Competências de Autoaprendizagem.

\begin{abstract}
Moving pictures have been gaining, over time, more and more importance both in society and education. Cinema or documentary films, for example, have the ability to dynamically represent certain events that occurred in the real world and assist in the understanding of the contents taught, while promoting a relaxed and motivating environment. Based on this assumption, this article aims to present a qualitative case study conducted with 14 lower secondary education students in Portugal, to evaluate how moving images contribute to the development of self-learning skills in history classes in the dimensions considered: Active Learning, Initiative and Autonomy. The results showed that the use of this pedagogical strategy contributes to the development of self-learning skills specially in relation to motivation for learning, autonomy and individual initiative to deepen knowledge.
\end{abstract}

Keywords: Moving Pictures. Movies. History. Self-learning Skills.

Cite como

(ABNT NBR 6023:2018)

PINHEIRO, Miguel; DIAS-TRINDADE, Sara; ALVES, Pedro. Imagens em movimento nas aulas de história e o seu impacto no desenvolvimento de competências de autoaprendizagem em estudantes da educação básica. Dialogia, São Paulo, n. 37, p. 1-13, e19356, jan./abr. 2021. Disponível em: https://doi.org/10.5585/dialogia.n37.19356

American Psychological Association (APA)

Pinheiro, M., Dias-Trindade, S., \& Alves, P. (2021, jan./abr.). Imagens em movimento nas aulas de história e o seu impacto no desenvolvimento de competências de autoaprendizagem em estudantes da educação básica. Dialogia, São Paulo, 37, p. 1-13, e19356.

https://doi.org/10.5585/dialogia.n37.19356. 
PINHEIRO, Miguel; DIAS-TRINDADE, Sara; ALVES, Pedro. Imagens em movimento nas aulas de história e o seu impacto no desenvolvimento de competências de autoaprendizagem em estudantes da educação básica

Introdução

Vivemos atualmente num mundo em que as pessoas e, sobretudo os adolescentes, parecem ter cada vez menos interesse na leitura, prestando mais atenção às redes sociais e às tecnologias audiovisuais. A observação e o contacto diário com jovens, leva-nos a afirmar que, nos dias de hoje, a tendência da juventude é adquirirem informação visualizando um vídeo no computador, no tablet, no telemóvel, na televisão ou noutro dispositivo tecnológico à sua disposição, em vez de ler um livro ou olhar para um jornal. As tecnologias e a internet permitiram aos adolescentes adquirir um conhecimento imediato, rápido e fácil em todo o lado e a qualquer momento, sem terem que perder tempo a procurar as suas respostas em bibliotecas ou mergulhar os seus olhos no papel.

Cientes desta realidade os professores de História devem criar na sala de aula um ambiente de aprendizagem dinâmico e flexível, mais interativo com os alunos, que tenha associado à componente pedagógica uma componente lúdica, de forma a tornar a aprendizagem da disciplina mais interessante e motivadora. É essencial conhecer o "mundo" dos estudantes, os seus gostos, as suas histórias e adaptarmos constantemente as nossas metodologias de trabalho tendo isso em consideração.

Optou-se por verificar a utilização das imagens em movimento enquanto recurso de aprendizagem permitia desenvolver nos alunos competências de autoaprendizagem, como é o caso da autonomia e da iniciativa individual em procurar conhecer mais sobre os temas abordados ao longo do ano letivo. Acredita-se que a autonomia é uma das principais competências que um estudante deve desenvolver durante o seu percurso letivo, de forma a o ajudar no seu futuro profissional. No que toca à recolha de dados, para o primeiro tipo de competências os mesmos foram adquiridos, essencialmente, através de observações pessoais, já no caso do segundo, utilizamos a Escala de Competência de Autoaprendizagem - ECAA (LIMA SANTOS; RURATO; FARIA, 2000) para obter as informações necessárias.

\section{As imagens em movimento em contexto educativo}

Segundo o dicionário Priberam, o termo imagem deriva do latim imago que significa "representação". Já o conceito de movimento, de acordo com o mesmo dicionário, significa "ato ou efeito de mover ou de mover-se", portanto, podemos definir as imagens em movimento como a representação de elementos em movimento. Para tornar esta definição mais completa, devemos acrescentar o facto de o movimento surgir quando se coloca um conjunto de imagens fixas numa sequência temporal. O tempo, sendo a condição para a expressão e experiência de algo, é que irá representar esses elementos de uma forma mais concreta ou abstrata. 
PINHEIRO, Miguel; DIAS-TRINDADE, Sara; ALVES, Pedro. Imagens em movimento nas aulas de história e o seu impacto no desenvolvimento de competências de autoaprendizagem em estudantes da educação básica

As imagens em movimento são igualmente uma linguagem específica audiovisual, com diferentes tipos e géneros, tais como: séries, de televisão ou de internet; documentário televisivo e ficção televisiva; curtas ou longas metragens; vídeo-ensaio e vídeo-aula e cinema, de ficção, científico/documental ou experimental. Relativamente aos géneros cinematográficos que existem atualmente, são os seguintes: ação, aventura, animação, biografia, comédia, crime, documentário, drama, família, fantasia, film-noir, game-show, história, terror, musical, mistério, notícias, reality-TV, romance, ficção científica, desporto, talk-show, thriller, guerra, western e adultos (IMDB, 2020). Cada tipo de imagem em movimento, de forma a ser corretamente e devidamente trabalhado, requer um estudo rigoroso, por isso, e tendo em conta a natureza e a dimensão deste trabalho, apenas iremos abordar mais pormenorizadamente o cinema, como um exemplo do potencial didático das imagens em movimento.

Tendo em conta a sociedade digital em que vivemos e os diversos meios de difusão de informação que existem ao nosso dispor atualmente, há que pensar em alternativas ao manual escolar (SILVA, 2009), pois ao utilizar apenas esse recurso, os alunos não terão acesso a uma visão distinta ou mais alargada da realidade. O manual, por vezes, não contém ou explora todos os aspetos necessários para compreender corretamente determinada matéria. Por essa mesma razão, é importante utilizar outros instrumentos, de forma a proporcionar aos estudantes uma aprendizagem mais profunda e enriquecedora (FERREIRA, 2010, p. 16).

Há que evitar o formato de aula expositiva, carregar os alunos com informação para memorizar ou simplesmente "debitar" no momento do teste de avaliação. O ensino nos nossos dias não deve ser visto nesses moldes, mas sim como um momento para incrementar uma aprendizagem diversificada e, ao mesmo tempo, rica em conhecimento e significado para o aluno. Dessa forma,

os audiovisuais podem desempenhar um papel decisivo porque ao serem um novo emissor, podem também desencadear novas formas de compreensão da mesma mensagem [...] o aluno pode passar a ser um construtor do seu conbecimento, já que é desafiado para uma leitura e uma interpretação mais independente, fugindo às ideias que são transmitidas de forma expositiva e com um cunbo mais pessoal por parte do professor o que, por vezes, acaba por retirar alguma liberdade interpretativa ao aluno (CARVALHO, 2013, p. 6).

As imagens em movimento permitem ainda ao aluno ter uma melhor perceção dos assuntos abordados em aula, facilitando uma melhor perceção dos acontecimentos, criando no aluno uma imagem com a qual melhor se identifica ou através da qual melhor consegue compreender uma determinada ideia ou acontecimento (FIGUEIREDO, 2018).

O ensino tem como objetivo preparar o aluno para o futuro e para a sua vida adulta, não só lhe transmitindo conhecimentos e ferramentas úteis para aplicar um dia mais tarde, como 
PINHEIRO, Miguel; DIAS-TRINDADE, Sara; ALVES, Pedro. Imagens em movimento nas aulas de história e o seu impacto no desenvolvimento de competências de autoaprendizagem em estudantes da educação básica

também o ajuda a desenvolver certas competências-chave para o seu desenvolvimento como pessoa e como membro de uma comunidade. Nesse sentido, as imagens em movimento ajudam a desenvolver competências ao nível da informação e comunicação, das linguagens e dos textos, do raciocínio e da resolução de problemas, do pensamento crítico e criativo, do relacionamento interpessoal, do desenvolvimento pessoal e da autonomia, da sensibilidade estética e artística e ainda do saber técnico e das tecnologias.

A visualização de filmes nas aulas de História permite o desenvolvimento de competências relacionadas com a utilização de fontes para a produção de conhecimento, o tratamento de informação a partir de uma perspetiva crítica ou a análise de multiperspetivas. Podem ainda promover uma abordagem da ciência histórica baseada em critérios éticos e estéticos, devido aos estímulos visuais que proporcionam ao espetador e aos valores morais que, por vezes, tentam transmitir e ajudar os alunos a saber comunicar as suas ideias em História, tanto por escrito, como oralmente, de forma individual ou em grupo. Como refere Dias-Trindade (2020),

a possibilidade de atrair os estudantes para diferentes contextos históricos, pode contribuir para a construção de uma perceção do passado, fundamentada e contextualizada, para além de construir representaçöes da realidade, conseguindo fazer emergir diferentes formas de ver, de sentir ou de pensar ( $p$. 140).

Segundo Pérez García e Muñoz Ruíz (2014):

el cine puede ser un agente preventivo si al espectador se le capacita para el análisis y la crítica de aquellas situaciones argumentales, simbolos o mensajes que orienten sobre los riesgos a evitar, o que apoyen el desarrollo de posiciones más maduras y el aianzamiento de valores. Conviene recordar que el hecho de trabajar con imágenes facilita los procesos de construcción socio-cognitiva de los aprendizajes y hace que estos sean mucho más enriquecedores (p. 119).

Trabalhar devidamente imagens em movimento em sala de aula não é uma tarefa fácil. Um vídeo, quer seja mostrado numa aula de História, de Filosofia, de Geografia, de Cidadania, ou noutra disciplina, antes de ser utilizado, deve ser devidamente estudado e preparado. Deve ser visto e analisado pelo professor com muita atenção, de forma que não seja meramente um momento lúdico para o estudante (CAMACHO, 2018, p. 14), pois apesar de ter essa vertente, um filme ou outro recurso audiovisual deve, acima de tudo, ter uma função prática, tornando os alunos menos passivos e mais ativos na sua aprendizagem (RANCIĖRE, 2009). No caso do cinema, por exemplo, não é apenas aquilo que está à vista que interessa, mas também o que está por detrás.

Há que ter em conta que a utilização deste tipo de recursos em sala de aula depende da opinião de cada docente. Não é que as pessoas neguem a utilidade deste tipo de recurso, simplesmente os professores continuam a debater-se com o reduzido tempo letivo que dispõem semanalmente para lecionar o programa na totalidade e, por isso, alguns afirmam não ter tempo 
PINHEIRO, Miguel; DIAS-TRINDADE, Sara; ALVES, Pedro. Imagens em movimento nas aulas de história e o seu impacto no desenvolvimento de competências de autoaprendizagem em estudantes da educação básica

nem disponibilidade para trabalhar um filme e mostrá-lo em sala de aula (DIAS-TRINDADE; RIBEIRO, 2016, p. 30).

Tendo em conta a faixa etária elevada do corpo docente na maioria das escolas, a dimensão dos programas curriculares e o reduzido tempo letivo que os professores dispõem para os lecionar, é normal que as imagens em movimento sejam colocadas de lado em muitas escolas. Analisar devidamente um vídeo/filme exige tempo e trabalho que muitos docentes não pretendem despender, preferindo em contraponto, utilizar recursos com os quais se sintam mais à vontade e que já tenham utilizado previamente. No entanto, recorrer a um simples fragmento de um vídeo/filme para ilustrar ou explicar certos aspetos de cada disciplina ou, ainda, possibilitar aos alunos o contacto com a realidade e permitindo-lhes realizarem o seu próprio filme, pesquisando e estudando eles próprios sobre determinado assunto, com o auxilio do professor (BERGALA, 2007) são excelentes opções para lecionar os conteúdos programáticos e motivar os estudantes nas suas aprendizagens, promovendo não só conhecimentos académicos, mas também competências transversais, tal como assinalado no documento Perfil dos Alunos à Saída da Escolaridade Obrigatória (MARTINS, 2017). O desenvolvimento de princípios, valores e competências, que estão presentes neste documento, por parte dos alunos é fulcral na atualidade. Tendo em conta as mudanças constantes que o mundo atravessa, é importante prepará-los corretamente para qualquer eventualidade futura e necessária adaptação.

\section{Metodologia}

Este estudo foi desenvolvido numa escola de educação básica em Portugal e envolveu 14 participantes, com uma média de idades de 12 anos. Ressalva-se que apesar de o projeto que serviu de base a este estudo, não ter sido submetido à apreciação de uma comissão de ética, não deixou de seguir as orientações éticas constantes da Carta Ética publicada pela Sociedade Portuguesa de Ciências da Educação (SPCE, 2014). Durante todo o processo investigativo os autores mantiveram elevados níveis de vigilância e autoreflexividade em relação às questões éticas, tal como defendido por (MAINARDES; CARVALHO, 2019).

Devido à dimensão deste trabalho e desta investigação, optamos por realizar um estudo de caso, sobretudo pela sua natureza descritiva, fenomenológica e qualitativa (BELL, 1993; YIN, 1989), com o objetivo de verificar se as imagens em movimento contribuem para o desenvolvimento de competências de autoaprendizagem nas aulas de História.

Para tal baseámo-nos na Escala de Competência de Autoaprendizagem - ECAA (LIMA SANTOS; RURATO; FARIA, 2000) no que diz respeito às diferentes dimensões consideradas: 
PINHEIRO, Miguel; DIAS-TRINDADE, Sara; ALVES, Pedro. Imagens em movimento nas aulas de história e o seu impacto no desenvolvimento de competências de autoaprendizagem em estudantes da educação básica

Aprendizagem Ativa, Iniciativa e Autonomia. O conceito de autoaprendizagem remete para "uma atitude de abertura em relação às oportunidades de aprendizagem proporcionadas pelas experiências do dia-a-dia e [para] a capacidade de utilizar de forma eficaz essas experiências formais ou informais”. (FARÍA et al, 2000, p. 206).

Os itens desta escala subdividem-se em três vertentes:

1. Aprendiragem Ativa ou Aceitação da Responsabilidade Pessoal, ou seja, avalia a capacidade do aluno para aprender com certa estratégia pedagógica e o seu envolvimento nesse processo;

2. Iniciativa na Aprendizagem e Orientação para a Experiência, que avalia a forma como o aluno orienta o seu próprio processo de ensino-aprendizagem ao longo do ano letivo.

3. Autonomia na Aprendizagem, que, como o próprio nome indica, avalia a autonomia do aluno no decurso das aulas e no sentido de aumentar o seu próprio conhecimento.

Isto significa que um dos objetivos principais desta investigação foi implicar o aluno na sua própria aprendizagem, isto é, torná-lo num agente ativo durante esse processo, de forma a aprofundar o seu conhecimento com algum auxílio por parte do professor. Essa iniciativa para procurar mais informação, permite complementar as aprendizagens lecionadas nas aulas de História e enriquecer o conhecimento de cada estudante.

Procedeu-se à análise do conteúdo (BARDIN, 1977; VALA, 1986), e dividiram-se as respostas, de acordo com a seguinte critério:

a) Resposta positiva;

b) Resposta negativa;

c) Resposta neutra.

Os dados foram também apresentados em tabelas, para facilitar a leitura da informação e dar relevância a algumas respostas por parte dos alunos.

\section{Apresentação de resultados e discussão}

Como já referimos anteriormente, os jovens, atualmente, contactam todos os dias com imagens em movimento. Quer seja a ver televisão, ver vídeos no YouTube, jogar videojogos, ver filmes e séries numa plataforma de streaming, ou mesmo indo ao cinema, as imagens em movimento estão à nossa volta e é impossível desligarmo-nos delas. Por essa razão, aplicá-las numa aula de História, aparenta ser uma boa opção, desde que sejam bem trabalhadas e que não sirvam apenas como uma forma de ilustração e de passar o tempo (ALENCAR, 2007, p. 116). 
PINHEIRO, Miguel; DIAS-TRINDADE, Sara; ALVES, Pedro. Imagens em movimento nas aulas de história e o seu impacto no desenvolvimento de competências de autoaprendizagem em estudantes da educação básica

No que respeita à primeira vertente, Aprendizagem Ativa ou Aceitação da Responsabilidade Pessoal (Tabela 1), todas as respostas foram positivas. A maioria destacou que a utilização das imagens em movimento facilitou a aprendizagem dos conteúdos.

Tabela 1 - Aprendizagem Ativa

\begin{tabular}{|l|l|}
\hline ES11 & $\begin{array}{l}\text { Acho que os vídeos facilitaram muito a minha aprendizagem porque às vezes tenho dificuldade em } \\
\text { só ouvir imaginar, vendo o video consegui idealizar certos momentos da bistória como aquele excerto } \\
\text { que vimos do Gladiador que deu uma breve ideia dos tempos romanos. (UR11) }\end{array}$ \\
\hline $\mathbf{E S 1 3}$ & $\begin{array}{l}\text { Aprendi a retirar dos filmes / vídeos informaçoes relativamente ao que aprendemos nos periodos, } \\
\text { fazendo pequenos resumos. O visionamento dos filmes/vídeos facilitaram-me a aprendiragem dos } \\
\text { conteúdos de cada periodo, porque eram uma forma diferente de se perceber a matéria e ao mesmo } \\
\text { tempo relacionar algumas coisas que nunca tínhamos aprendido com as que aprendemos. (UR13) }\end{array}$ \\
\hline $\mathbf{E S 1 2}$ & $\begin{array}{l}\text { Sim, sendo este método de ensino mais interativo despertou-me mais o conhecimento para a matéria, } \\
\text { que outrora me parecia "uma seca". (UR12) }\end{array}$ \\
\hline
\end{tabular}

Fonte: Dos autores.

Como podemos observar pela Tabela 1, nesta primeira vertente, o estudante ES11 referiu que os vídeos facilitaram muito a sua aprendizagem, permitindo-lhe observar (no caso dos filmes de ficção) certos acontecimentos históricos a desenrolarem-se perante os seus olhos, dando-lhe, por isso, um olhar mais claro sobre os períodos estudados e os seus protagonistas: [...] consegui idealizar certos momentos da história como aquele excerto que vimos do Gladiador que deu uma breve ideia dos tempos romanos (UR11).

O estudante ES13 referiu igualmente que os filmes e vídeos facilitaram a sua aprendizagem, porque eram uma forma diferente de se perceber a matéria (UR13). Para além disso, surgiram também como uma oportunidade para aprender novos conteúdos, que se interligavam com aqueles que já tinham sido abordados previamente: [...] ao mesmo tempo relacionar algumas coisas que nunca tínhamos aprendido com as que aprendemos.

Já o estudante ES12, referiu que esta estratégia despertou mais o seu interesse pela matéria abordada.

De forma a mostrar mais algumas opiniões dos alunos nesta vertente, podemos ainda acrescentar as seguintes respostas: 
PINHEIRO, Miguel; DIAS-TRINDADE, Sara; ALVES, Pedro. Imagens em movimento nas aulas de história e o seu impacto no desenvolvimento de competências de autoaprendizagem em estudantes da educação básica

- ES5 - Sim, acho que os vídeos/filmes etc. facilitaram bastante a minha aprendizagem na disciplina, porque fica muito mais fácil de entender a matéria e também cativa mais a nossa aprendizagem! (UR5)

- ES8 - Sim, aprendi, pois, os vídeos/filmes de alguma forma representam o assunto que estamos a estudar, ou seja, dá para ver como era [...] (UR8)

- ES14 - Eu gostei muito desse método de ensino porque era um estilo de ensino melhor, mas é estranho para mim porque era novo. Aprendi coisas com os filmes/vídeos visualizados, aprendi prestando atenção nas imagens e legendas que apareciam (nos filmes), mas nos vídeos eu prestava atenção no som. Os filmes facilitaram a minha aprendizagem, porque se virmos filmes ou videos, ficamos mais concentrados do que alguém a falar. Consegui ligar facilmente os vídeos/filmes à matéria. (UR14)

- ES3 - Eu gostei muito dos filmes e dos vídeos porque é uma abordagem diferente do normal estamos a aprender sem dar conta (UR3)

No geral, praticamente todos mencionaram que este método facilitou as suas aprendizagens, permitindo visualizar e ter uma melhor perceção dos conteúdos históricos lecionados. Outros referiram que, apesar de ser diferente, é melhor do que um formato de aula expositiva. E outros, escreveram que este método se apresenta como um método mais motivador e cativante para aprender História. Estas conclusões estão de acordo com as de outros autores, como Ferreira (2010), Reigada (2013), Figueiredo (2018) e Dias-Trindade e Moreira (2019).

Figueiredo (2018) refere que as imagens em movimento

acrescentam uma maior dinâmica à difusão de conteúdos, pois despertam a atenção, aumentam a curiosidade e da sua visualização obtêm-se aprendizagens [...] (p. 83).

$\mathrm{Na}$ segunda vertente, Iniciativa na Aprendizagem e Orientação para a Experiência (Tabela 2), todas as respostas tiveram igualmente um caráter positivo - 14 positivas / 0 negativas / 0 neutras. A maioria referiu que retirou dos vídeos e filmes informações úteis para as suas aprendizagens. 
PINHEIRO, Miguel; DIAS-TRINDADE, Sara; ALVES, Pedro. Imagens em movimento nas aulas de história e o seu impacto no desenvolvimento de competências de autoaprendizagem em estudantes da educação básica

Tabela 2 - Iniciativa na Aprendizagem e Orientação para a Experiência

\begin{tabular}{|l|l|}
\hline ES14 & $\begin{array}{l}\text { Compreendi como poder utilizar os videos/filmes para os meus conhecimentos e ajudar-me } \\
\text { nas aprendizagens. Os videos/filmes ajudaram-me um pouco na participação para alguns } \\
\text { recursos visualizados. Eu sinto que consegui retirar alguma informação útil para as minhas } \\
\text { aprendizagens. Acho que me esforcei mais um bocado para aprender. (UR28) }\end{array}$ \\
\hline ES1 & $\begin{array}{l}\text { Sinto que os videos e filmes têm me ajudado a retirar informações úteis para as minhas } \\
\text { aprendizagens e estou a esforçar-me para aprender sempre mais a partir dos recursos } \\
\text { visualizados. (UR15) }\end{array}$ \\
\hline $\begin{array}{l}\text { Eelhorei as minhas aprendizagens ao visionar os filmes/vídeos, porque percebi como utilizar } \\
\text { os seus conhecimentos. Consegui participar de forma ativa nos debates sobre os recursos } \\
\text { visualizados, pois aprendo mais com este método. Usando este método (visualizar } \\
\text { filmes/videos) retirei todas as informaçoes uteis e ainda mais para as minhas aprendizagens. } \\
\text { Adorei tanto a ideia de visualizar filmes/vídeos que me esforcei sempre para tirar mais } \\
\text { informação. (UR27) }\end{array}$ \\
\hline
\end{tabular}

Fonte: Dos autores.

Na Tabela 2, podemos observar que o estudante ES14 referiu que a visualização dos vídeos e filmes o ajudou a conseguir participar um pouco mais nos debates sobre esses mesmos temas. Já o estudante ES1, mencionou que se esforçou para aprender sempre mais a partir dos recursos visualizados (UR15), o que demonstra que o interesse pelas imagens em movimento fez com que o aluno procurasse adquirir mais conhecimentos sobre o que via.

Alencar (2007) concluiu também que:

[...] o cinema nas aulas de história desperta no educando a curiosidade e a motivação para a pesquisa com o intuito de alargar o conbecimento sobre o que foi visto (p. 143).

O estudante ES13 mencionou que melhorou as suas aprendizagens ao visionar os filmes/vídeos, porque (percebeu) como utilizar os seus conhecimentos (UR27). No fundo, o que este aluno quis dizer, é que conseguiu conectar aquilo que viu com aquilo que já tinha aprendido anteriormente, permitindo-lhe aumentar os seus conhecimentos e melhorar as suas aprendizagens.

Acrescentamos ainda as seguintes respostas, por considerarmos serem igualmente importantes de partilhar com o leitor:

- ES11 - Sim, consegui também perceber melhor, e se precisar de ver outra veź é só perguntar o nome do vídeo ao professor e vejo em casa como parte do estudo. (UR25)

- ES9 - Sim em algumas matérias os recursos visualizados foram úteis. Esforcei me ao máximo. (UR23)

- ES8 - Sim, posso retirar as informações úteis para melhorar a minha aprendizagem, mas mesmo com vídeos/filmes continuo a participar pouco, nessa parte não me influenciou. (UR22)

- ES3 - Para mim foi mais fácil adquirir os conhecimentos da matéria sempre que foram utilizados os recursos filmes/videos. (UR17) 
PINHEIRO, Miguel; DIAS-TRINDADE, Sara; ALVES, Pedro. Imagens em movimento nas aulas de história e o seu impacto no desenvolvimento de competências de autoaprendizagem em estudantes da educação básica

Com exceção do estudante ES8, que referiu que, embora os recursos audiovisuais lhe tenham permitido retirar informações úteis (UR22) para a sua aprendizagem, não o motivaram a participar mais nas aulas, os restantes deram mais uma vez respostas bastante positivas, indicando que conseguiram aprender mais com os vídeos/filmes e que os levou a esforçarem-se mais para aprender e tirar melhores resultados.

Por último, na vertente Autonomia na Aprendiragem (Tabela 3), os 14 alunos que responderam ao inquérito, demonstraram ter tido alguma autonomia, sobretudo no que toca a acabar de ver os filmes em casa. No total contam-se 14 respostas positivas, 0 negativas e 0 neutras.

\section{Tabela 3 - Autonomia na Aprendizagem}

\begin{tabular}{|l|l|}
\hline ES11 & $\begin{array}{l}\text { Sim, achei muito interessante e produtivo ver os vídeos para não ser sempre aulas a } \\
\text { "descarregar" matéria, então cheguei a casa e vi o Gladiador e os outros videos outra vez: } \\
\text { (UR39) }\end{array}$ \\
\hline ES13 & $\begin{array}{l}\text { Tive interesse em saber mais, procurando em sites, livros, revistas e outro tipo de fontes. Ao } \\
\text { longo do meu percurso olharei para os filmes/vídeos de forma diferente, pois terei aprendido } \\
\text { coisas novas acerca da história. Desde pequena nunca tive muito interesse em história, mas } \\
\text { ao ver os filmes/vídeos consegui olhar para a história com outros olhos e perceber que a } \\
\text { bistória é muito importante na nossa vida, porque sem ela não sabiamos com era o nosso } \\
\text { passado [...]. (UR41) }\end{array}$ \\
\hline ES10 & $\begin{array}{l}\text { Sim achei interessante ver os vídeos pois facilita muito os estudos e quando cheguei a casa vi } \\
\text { os filmes e os vídeos outra vez. (UR38) }\end{array}$ \\
\hline
\end{tabular}

Fonte: Dos autores.

Na Tabela 3, podemos ver que os estudantes ES10 e ES11 tiveram curiosidade em terminar de ver os filmes e vídeos visualizados nas aulas, em casa. Já o aluno ES13 procurou mais informações em sites, livros, revistas e outro tipo de fontes (UR41) e referiu que, apesar de história não ser a sua disciplina favorita, estes recursos permitiram olhar para esta ciência com outros olhos (UR41).

As respostas seguintes, embora não tenhamos dado maior relevância para colocar entre as três que se encontram na tabela, estão igualmente na mesma linha de pensamento que as anteriores: 
PINHEIRO, Miguel; DIAS-TRINDADE, Sara; ALVES, Pedro. Imagens em movimento nas aulas de história e o seu impacto no desenvolvimento de competências de autoaprendizagem em estudantes da

- ES5 - Sim, por exemplo quando não temos tempo de acabar de ver o filme eu em casa ia acabar de o ver! Sim os filmes motivaram me para aprender mais sobre história! (UR33)

- ES1 - Tive interesse em procurar mais sobre a matéria que damos em cada aula, os vídeos e filmes têm me motivado a aprender mais sobre história e acho que vou conseguir relacionar mais conhecimentos de história com filmes que tenham conteúdo histórico. (UR29)

- ES12 - Eu acho que a ideia de utilizar excertos de filmes não só nos dá curiosidade para ver o resto como para pesquisa/saber mais sobre o tema do qual se trata o filme. (UR40)

- ES7 - Sim, tive curiosidade em ver os filmes visualizados na aula e embora não goste muito de História deu-me interesse em aprender mais. (UR35).

Como Reigada (2013) indica,

A utilização do filme não se esgota no seu carácter motivacional inicial. O filme tem uma presença constante na mente dos alunos, que intensifica o interesse e a curiosidade à medida que o conbecimento que se tem sobre o mesmo se vai aprofundando (p. 345).

Em suma, não só os estudantes demonstraram aprender mais facilmente com esta estratégia pedagógica, como afirmaram que se sentiram mais interessados e motivados para aprender História e para participar nos debates sobre os vídeos e filmes visualizados.

\section{Conclusão}

Em termos pedagógico-educativos, o manual não é nem deve ser, o único recurso de informação para um professor de História. Continuar a lecionar, no ensino básico e secundário, como se fazia há uma década atrás, é impensável. Praticamente todos os alunos vão acabar por se “desligar”, eventualmente, se as aulas seguirem sempre a mesma estratégia pedagógica.

Vivemos tempos desafiantes no ensino por essa mesma razão. Não se trata simplesmente de chegar a uma sala de aula, pedir aos alunos para abrirem o livro numa certa página e começar a debitar matéria. Não só o nível e a qualidade do processo de ensino-aprendizagem vai ser limitado, como, mais importante ainda, os estudantes não se vão sentir verdadeiramente interessados por História, nem motivados para adquirir mais conhecimentos da disciplina. Tendo em conta este cenário, as imagens em movimento surgem como um recurso e uma estratégia diferente ao status quo do ensino habitual e como uma forma de desenvolver importantes competências ao nível da autoaprendizagem.

Esta investigação permitiu-nos concluir que o interesse dos alunos pelas temáticas abordadas aumentou quando era mostrado um excerto de um bom vídeo, de um bom filme, ou de um bom documentário. Esse interesse e motivação para procurar saber mais sobre os assuntos refletiram-se nas várias questões e observações que os estudantes fizeram sobre os conteúdos 
PINHEIRO, Miguel; DIAS-TRINDADE, Sara; ALVES, Pedro. Imagens em movimento nas aulas de história e o seu impacto no desenvolvimento de competências de autoaprendizagem em estudantes da

visualizados e no facto de procurarem terminar de ver o filme mostrado. Para além disso, verificouse também alguma evolução nas várias competências presentes no Perfil dos Alunos à Saída da Escolaridade Obrigatória (MARTINS, 2017), tais como: análise de outro tipo de linguagem (neste caso a linguagem audiovisual); informação e comunicação; raciocínio e resolução de problemas e pensamento crítico e criativo (pedindo aos alunos que respondessem a questões tanto oralmente, como por escrito e refletissem sobre aquilo que viam, tendo, não só, em conta a temática da obra, como também, as incongruências históricas num filme de ficção (Ex: "O Gladiador" ou o filme “Ágora"); desenvolvimento pessoal e autonomia; sensibilidade estética e artística e saber cientifico, técnico e tecnológico. Não esquecer ainda a importância das imagens em movimento no que respeita a transmitir e ensinar certos valores aos alunos, ajudando-os, dessa forma, a se desenvolverem tanto pessoal como civicamente.

Numa época em que a imagem domina o quotidiano dos jovens, um excerto de um filme, um documentário ou uma série, podem ter o poder de motivar um aluno, desenvolver o seu espírito crítico e, mais importante ainda, gerar interesse e curiosidade pelo ensino e pela aprendizagem da História.

\section{Referências}

ALENCAR, Sylvia Elisabeth de Paula; O cinema na sala de aula: Uma aprendizagem dialógica da disciplina de História; Dissertação de mestrado; Fortaleza - Ceará, 2007.

BARDIN, L. L'analyse de contenu. Paris: PUF, 1977.

BERGALA, Alain. La Hipótesis Del Cine: Pequeño tratado sobre la transmisión del cine en la escuela y fuera de ella; Barcelona: Laertes Educatión, 2007.

CAMACHO, João Carlos Orta. Os alunos de Lumière: Experiência de inclusão do Cinema na Didática da História da Cultura e das Artes. Lisboa: Faculdade de Ciências Sociais e Humanas, 2018.

CARVALHO, António Manuel Gomes. A importância do documentário na aula de História e da reportagem na aula de Geografia no ensino básico e secundário. (relatório de mestrado). Braga:

Universidade do Minho, 2013.

DIAS-TRINDADE, Sara. Moving pictures: a way of understanding and studying history in higher education. In Abellán-García Barrio, Á. (coord.). Cada imagen es un mundo. Madrid: Editorial Sindéresis, 2020. p. 135-148

DIAS-TRINDADE, Sara; MOREIRA, José António; Pedagogical scenarios enriched with audiovisual technologies and their impact on the promotion of the learning skills of inmate students in Portugal. Digital Education Review, v. 35, June 2019. 97-110. DOI:

https://doi.org/10.1344/der.2019.35.97-110. 
PINHEIRO, Miguel; DIAS-TRINDADE, Sara; ALVES, Pedro. Imagens em movimento nas aulas de história e o seu impacto no desenvolvimento de competências de autoaprendizagem em estudantes da

DIAS-TRINDADE, Sara; RIBEIRO, Ana Isabel. O espaço do cinema na didática da História. Revista de Linguagem do Cinema e do Audiovisual, v. 5, n. 2. 2016. 27-34.

FARIA, Luísa; RURATO, Paulo; SANTOS, Nelson Lima. Papel do auto-conceito de competência cognitiva e da auto-aprendizagem no contexto sócio-laboral. Análise Psicológica, 2 (XVIII), 2000. s.p.

FERREIRA, Eurico Costa. O uso dos audiovisuais como recurso didático. (Relatório de Mestrado). Porto: Faculdade de Letras da Universidade do Porto, 2010.

FIGUEIREDO, Sérgio Oliveira. O cinema e a História: A utilização do cinema no processo de tese (Relatório de Mestrado). Lisboa: Universidade de Lisboa, 2018.

GARCÍA, Álvaro Pérez; RUÍS, Daniel Muñoz. Análisis didáctico de narrativa audiovisual, in ALVES, Luís Alberto; GARCÍA GARCÍA, Francisco; ALVES, Pedro (orgs.) Aprender del cine: narrativa y didáctica. Madrid: ICONO14 Editorial, 2014. p. 111-148

MAINARDES, Jefferson, \& CARVALHO, Isabel Cristina de Moura. Autodeclaração de princípios e de procedimentos éticos na pesquisa em Educação. In ANPEd - Associação Nacional de Pós-Graduação e Pesquisa em Educação. Ética e Pesquisa em Educaşão. Subsídios. v. 1, p. 129-132, Brasil: ANPEd, 2019.

MARTINS, Guilherme d'Oliveira (coord.). Perfil dos alunos à saída da escolaridade obrigatória. Lisboa: Ministério da Educação, 2017.

RANCIÈRE, Jacques. The Emancipated Spectator. Nova Iorque: Verso, 2009.

REIGADA, Tiago. Ensinar com a sétima arte: O espaço do cinema na Didática da História. (Tese de Doutoramento). Porto: Faculdade de Letras da Universidade do Porto, 2013.

SILVA, Marcos. História, filmes e ensino: desavir-se, reaver-se. In NÓVOA, Jorge, FRESSATO, Soleni Biscouto; FEIGELSON, Kristian (coord.). Cinematógrafo: Um olhar sobre a História (pp. 147-158). Salvador: Editora UNESP, 2009.

SPCE - Sociedade Portuguesa de Ciências da Educação. Carta Ética. Instrumento de regulação éticodeontológica. Porto: SPCE.

TAVARES, Marisa Ferreira. Vem e vê: a utilização do filme no processo de ensino-aprendizagem de História e de Geografia. (Dissertação de Mestrado). Porto: Faculdade de Letras da Universidade do Porto, 2011.

VALA, J. A. Análise de conteúdo. In SILVA, A.; PINTO, J. (eds.). Metodologia das Ciências Sociais. Porto: Edições Afrontamento, 1986. s.p. 